\title{
Mortality Statistics for Multiple Sclerosis and Amyotrophic Lateral Sclerosis in Sweden
}

\author{
Inger Boström ${ }^{a}$ Trond Riise ${ }^{d}$ Anne-Marie Landtblom ${ }^{a}$, b, c \\ ${ }^{a}$ Division of Neuroscience, Department of Clinical and Experimental Medicine, Linköping University, and \\ ${ }^{b}$ Neurology Clinic, University Hospital, Linköping, and ' Neurology Unit, General Hospital, Motala, Sweden; \\ ${ }^{\mathrm{d}}$ Department of Public Health and Primary Health Care, University of Bergen, Bergen, Norway
}

\section{Key Words}

Amyotrophic lateral sclerosis - Multiple sclerosis •

Mortality $\cdot$ Correlation

\section{Abstract}

Background: Multiple sclerosis (MS) and amyotrophic lateral sclerosis (ALS) are chronic neurologic diseases for which distinct explanations of the pathogenesis are lacking. Two large Swedish register studies have rather unexpectedly detected a correlation between MS and ALS. The aim of this study was to investigate if an association between ALS and MS could be demonstrated as has been shown earlier. Material and Methods: Data on mortality from ALS and MS, 19902010, were collected from the Swedish National Statistics Office. In all there were 5,696 deaths due to ALS and 3,941 deaths due to MS. Age- and sex-adjusted mortality rates were calculated. Results: There was no correlation between the mortality rates of ALS and MS in the 21 counties of Sweden for the period 1990-2010 (Spearman's rho $=-0.052 ; p=$ $0.822 ; \mathrm{n}=21$ ). The national mean mortality rate for ALS throughout the period of 1990-2010 was 2.98 per 100,000 person-years (95\% Cl 2.87-3.08). For MS the national mean mortality rate was 2.04 per 100,000 person-years $(95 \% \mathrm{Cl}$ 1.95-2.12). Conclusion: This study did not confirm the previously shown association between MS and ALS in Sweden.

Copyright $\odot 2012$ S. Karger AG, Basel

\section{Introduction}

Multiple sclerosis (MS) and amyotrophic lateral sclerosis (ALS) are chronic neurologic diseases for which distinct explanations of the pathogenesis are lacking. They have different clinical features and affect different patient groups regarding age and gender. Two large Swedish register studies have rather unexpectedly demonstrated a correlation between MS and ALS $[1,2]$. The recent article by Hemminki et al. [1] sheds light on the familial risk of MS. It contains data from 425,102 patients in the MigMed database, which has been compiled from several national Swedish registers provided by Statistics Sweden, including the Multigeneration Register in which persons (second generation) born in Sweden in 1932 and thereafter are registered shortly after birth and are linked to their parents (first generation). The familial risks of MS versus

\section{KARGER}

Fax +4161306 1234

E-Mail karger@karger.ch

www.karger.com (c) 2012 S. Karger AG, Basel

0251-5350/12/0384-0245\$38.00/0

Accessible online at:

www.karger.com/ned
Inger Boström

Division of Neuroscience, Department of Clinical and Experimental Medicine University of Linköping

SE-581 85 Linköping (Sweden)

Tel. +46550 88599, E-Mail inger.bostrom@kristinehamn.se 
autoimmune diseases, ALS and asthma were investigated. This study was the first population-based study on these diseases ever performed. The main finding was an almost doubled risk of MS for individuals with a parent diagnosed with ALS (standardized incidence ratio $=1.84$; 95\% CI 1.23-2.64).

Further, another large register study performed by two of the authors of this study [2] analyzed the geographical distribution of the mortality from MS in Sweden (5,425 died of MS, 1952-1992). To interpret the geographical variation in mortality, the MS data were compared with the mortality from ALS (5,088 died of ALS, 1961-1992), a methodological procedure sometimes used to control for factors that may systematically affect the prevalence figures, such as for example the access to specialized medical service. Unexpectedly, a high correlation rate between the mortality rates of MS and ALS in the 24 counties of Sweden was found (Pearson's $r=0.54, p=0.006$ ). In addition, this study showed that MS mortality was very high in the county of Värmland in western Sweden during four decades [2]. Other reports had previously supported a high occurrence of MS in this area [3], and interestingly, yet another team had demonstrated a high incidence of ALS in the same region $[4,5]$.

The aim of this study was to investigate if an association between the geographical distribution of the mortality from ALS and MS, as described above, could be demonstrated at a later period, using the mortality statistics of both diseases for all counties of Sweden during the time period following the one included in the previous study.

\section{Methods}

Data on mortality from ALS and MS from the Causes of Death Register and data from the Total Population Register during the time period 1990-2010 were collected from the Swedish National Statistics Office (Statistics Sweden) [6, 7]. During the time period considered in this study, both the Ninth Revision (ICD-9, for 1990-1996; codes 335C for ALS and code 340 for MS) and the Tenth Revision (ICD-10, for 1997-2010; codes G 12.2 for ALS and code 35.9 for MS) of the International Classification of Diseases were used.

In all there were 5,696 deaths due to ALS, 2,612 women (45.9\%) and 3,084 men (54.1\%), and 3,941 deaths due to MS, 2,372 women $(60.2 \%)$ and 1,569 men $(39.8 \%)$. The mortality statistics were based on death certificates, and the cause of death was registered as underlying or contributing, both modalities considered in the analysis.

Age- and sex-adjusted mortality rates were calculated using the direct standardization method [8] with the population of Sweden 1998 as the reference population [7]. The adjusted mortality rates of ALS and MS were calculated for age (10-year groups), gender, and county (21 counties) reported per year (1990-2010). The correlation between the mean mortality of ALS and of MS in the Swedish counties during 1990-2010 was estimated by the nonparametric Spearman's rho. Changes in the crude mortality rates between the period reported in the previous study and the one in the present study were tested using $\chi^{2}$ test. The Mann-Whitney test was used when comparing the mortality rates between ALS and MS.

The SPSS 13.0 software program was used for all statistical analyses. The study was approved by the Ethical Committee of the University of Linköping (D-nr 2010/340-31).

\section{Results}

Marked variation in the mean mortality rates between the 21 counties of Sweden was seen for both ALS and MS during the period 1990-2010 (table 1). There was no overall correlation between the mortality rates of ALS and MS (Spearman's rho $=-0.052 ; \mathrm{p}=0.822 ; \mathrm{n}=21$ ). To adjust for a possible effect due to the introduction of a new immunomodulating treatment for MS during the last years, we repeated the analysis for the subperiods 1990-2000 and 2001-2010. No significant correlation was found for any of these periods (Spearman's rho $=-0.062 ; \mathrm{p}=0.790 ; \mathrm{n}=$ 21 ; and Spearman's rho $=-0.149 ; \mathrm{p}=0.521 ; \mathrm{n}=21$, respectively).

When comparing the geographical distribution of the mortality rates of ALS in the time period 1961-1992 with the later period 1990-2010 there was no correlation (Spearman's rho $=-0.118 ; \mathrm{p}=0.610 ; \mathrm{n}=21$ ). However, when comparing the mortality rates of MS in the time period 1952-1992 with the later time period 1990-2010 there was a significant correlation (Spearman's rho = $0.664 ; \mathrm{p}=0.002 ; \mathrm{n}=21$ ).

The national mean mortality rate for ALS throughout the period of $1990-2010$ was 2.98 per 100,000 personyears (95\% CI 2.87-3.08), in women 2.72 (95\% CI $2.58-$ 2.86) and in men 3.23 (95\% CI 3.07-3.40). The national mean mortality rate for MS was 2.04 per 100,000 personyears (95\% CI 1.95-2.12), in women 2.43 (95\% CI 2.31 2.56) and in men 1.64 (95\% CI 1.54-1.74). The mortality of MS increased significantly in the country from the first time period, 1.65 per 100,000 person-years [2] to 2.04 in the second period $\left(\chi^{2}=4.36 ; \mathrm{p}=0.037\right)$. There was also a significant increase of mortality in ALS, between the two investigated periods, from 1.91 per 100,000 person-years [2] to $2.98\left(\chi^{2}=21.93 ; p<0.001\right)$. Finally, we found generally higher mortality rates for ALS compared with MS in the whole country during the time period 1990-2010 (fig. 1, Mann-Whitney $\mathrm{p}<0.001$ ). 
Table 1. Average annual population for each county, number of deaths, adjusted mortality rates per 100,000 person-years and percent of the total national mortality rate for ALS and MS, respectively (during the period 1990-2010) in the 21 counties of Sweden

\begin{tabular}{|c|c|c|c|c|c|c|c|}
\hline \multirow[t]{2}{*}{ County } & \multirow{2}{*}{$\begin{array}{l}\text { Average } \\
\text { population }\end{array}$} & \multicolumn{3}{|l|}{ ALS } & \multicolumn{3}{|l|}{ MS } \\
\hline & & $\begin{array}{l}\text { deaths } \\
\mathrm{n}\end{array}$ & $\begin{array}{l}\text { adjusted } \\
\text { mortality rate }\end{array}$ & $\begin{array}{l}\% \\
\text { total }\end{array}$ & $\begin{array}{l}\text { deaths } \\
\mathrm{n}\end{array}$ & $\begin{array}{l}\text { adjusted } \\
\text { mortality rate }\end{array}$ & $\begin{array}{l}\% \\
\text { total }\end{array}$ \\
\hline Stockholm & $1,820,917$ & 984 & 2.97 & 99.6 & 605 & 1.70 & 83.3 \\
\hline Uppsala & 298,953 & 211 & 3.74 & 125.5 & 122 & 2.17 & 106.3 \\
\hline Södermanland & 260,268 & 148 & 2.49 & 83.5 & 117 & 2.03 & 99.5 \\
\hline Östergötland & 415,115 & 229 & 2.54 & 85.2 & 171 & 1.92 & 94.1 \\
\hline Jönköping & 329,656 & 235 & 3.11 & 104.3 & 150 & 2.02 & 99.0 \\
\hline Kronoberg & 179,250 & 124 & 2.97 & 99.6 & 82 & 2.19 & 107.3 \\
\hline Kalmar & 237,511 & 164 & 2.85 & 95.6 & 105 & 1.94 & 95.0 \\
\hline Gotland & 57,510 & 38 & 2.95 & 98.9 & 16 & 1.30 & 63.7 \\
\hline Blekinge & 151,377 & 108 & 2.96 & 99.3 & 83 & 2.38 & 116.6 \\
\hline Skåne & $1,142,235$ & 751 & 3.10 & 104.0 & 484 & 2.02 & 9.0 \\
\hline Halland & 276,884 & 184 & 3.04 & 102.0 & 126 & 2.17 & 106.3 \\
\hline Vä Götaland & $1,503,701$ & 904 & 2.95 & 98.9 & 803 & 2.39 & 117.1 \\
\hline Värmland & 277,806 & 182 & 2.28 & 76.5 & 177 & 2.76 & 135.2 \\
\hline Örebro & 275,178 & 199 & 3.15 & 105.7 & 147 & 2.38 & 116.6 \\
\hline Västmanland & 257,283 & 184 & 3.19 & 107.0 & 106 & 1.77 & 86.7 \\
\hline Dalarna & 281,865 & 188 & 2.80 & 93.9 & 125 & 1.92 & 94.1 \\
\hline Gävleborg & 281,605 & 206 & 3.09 & 103.6 & 142 & 2.19 & 107.3 \\
\hline Västernorrland & 250,445 & 181 & 2.99 & 100.3 & 104 & 1.71 & 83.8 \\
\hline Jämtland & 130,866 & 77 & 2.34 & 78.5 & 58 & 1.98 & 97.0 \\
\hline Västerbotten & 257,180 & 192 & 3.48 & 116.7 & 104 & 1.86 & 91.1 \\
\hline Norrbotten & 257,724 & 207 & 3.49 & 117.1 & 114 & 2.00 & 98.0 \\
\hline Sweden & $8,943,330$ & 5,696 & 2.98 & 100.0 & 3,941 & 2.04 & 100.0 \\
\hline
\end{tabular}

\section{Discussion}

This study failed to confirm the previously shown association between the mortality from MS and ALS, respectively, in Sweden. We cannot exclude that our previous finding was an artefact [2], as it was unexpected and could not be explained from any biological hypothesis. In fact, ALS and MS do not share many commonly suggested etiological factors that could account for such an association. Exceptions are cigarette smoking $[9,10]$ and exposure to organic solvents [11-13]. Other risk factors mentioned for MS are Epstein-Barr virus, vitamin D deficiency, female gender, and ethnicity [14] and for ALS, heavy manual labor [5]. There is also, to our knowledge, no evidence for an overlap in the genetic basis for MS and sporadic ALS. In MS there is an overrepresentation of the genes HLA DR 15, and other recently confirmed genes are for the alpha chains of interleukin receptors IL-2 and IL-7 [15], whereas no such association is known for ALS.

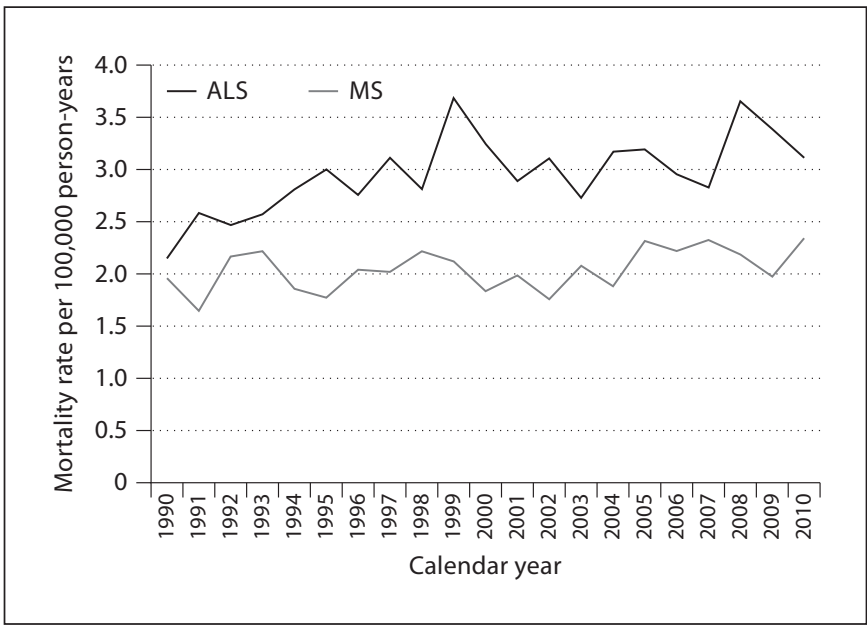

Fig. 1. Mortality rates of ALS and MS in Sweden during the time period 1990-2010. 
The previous finding of an association between MS and ALS [2] may have been the effect of differences in coding of diagnosis between the counties, for example a high reporting rate of neurological diagnoses during earlier periods in certain counties. However, the counties with a high frequency of MS, especially Värmland, had no specific resources for neurological diseases or MS, which could explain increased reporting. We used in the present study mortality statistics over 21 years, a rather long period, but the observation period in the previous study was even longer (40 and 30 years, respectively).

Mortality statistics represent, however, a crude instrument, and several factors could have influenced the results, both of our present study and the previous one. One such factor is the improved health care in Sweden with the availability of specific treatments. This has certainly had an impact on the outcome of various diseases, including mortality. Importantly, this is likely to affect MS rather than ALS mortality, because there is at present not an effective drug against ALS. Nevertheless, a better measure of any relation between MS and ALS could be achieved using incidence rates rather than mortality rates.

We found higher mortality rates of both MS and ALS in the present study compared to the previous study. This probably reflects a general increasing prevalence of the diseases that has previously been reported for MS [16]. Further, we found a significant correlation in the mortality rates for the counties between the two periods 1952 1992 and 1990-2010 for MS. No such correlation was found for ALS. We interpret these findings as an indication of a changed pattern in ALS mortality during the later period (1990-2010). Furthermore, we see an increased survival in the MS data (higher mean age at death), which may be an effect of immunomodulatory drugs. Still, analyzing the periods 1990-2000 and 20012010 separately did not change the results, suggesting that the lack of association between ALS and MS in this study was not caused by this increased use of treatment in MS.

Possible diagnostic errors are more likely to concern MS than ALS, and especially the diagnosis hereditary spastic paraplegia, which can mimic progressive MS, can be a problem. Nevertheless, the diagnostic precision in Sweden is generally high, and one study of the validity of the underlying cause of death in the Swedish Cause-ofDeath Register in 1995 showed that $77 \%$ of the cases in the register had a correct underlying diagnosis regarding cause of death [17]. Further, a large Swedish nationwide incidence study of ALS (1991-2005) showed that 78.6\% of the deceased individuals with ALS as underlying cause of death were also identified in the Inpatient Register [18]. The incidence study of ALS in the county of Värmland showed that $95 \%$ of the patients were captured by the death certificates [5].

The mortality statistics in this study included both the underlying and contributing cause of death, as well as in our previous study [2], which used both modalities, giving comparable conditions $[19,20]$.

Our previous mortality study reported crude rates, while we present age- and sex-adjusted rates in this study. Nevertheless, we find it unlikely that this difference could explain a correlation in the previous study that disappeared in the present study.

\section{Conclusion}

The results of the present study do not verify a persistent association between ALS and MS in Sweden. The data is, however, in our judgment, both valid and also congruent with other studies. Nevertheless, given the indirect measure of the disease used in the present study, mortality statistics, these data cannot be used to firmly exclude a possible association, as described in the study by Hemminki et al. [1]. Their results are hard to ignore and we encourage further observations and research on this issue.

\section{Disclosure Statement}

The authors declare no conflicts of interest.

References

1 Hemminki K, Li X, Sundquist J, Hillert J, Sundquist K: Risk for multiple sclerosis in relatives and spouses of patients diagnosed with autoimmune and related conditions. Neurogenetics 2009;10:5-11.

2 Landtblom AM, Riise T, Boiko A, Söderfeldt B: Distribution of multiple sclerosis in Sweden based on mortality and disability compensation statistics. Neuroepidemiology 2002;21:167-179.

3 Kurtzke JF: On the fine structure of the distribution of multiple sclerosis. Acta Neurol Scand 1967;43:257-282.

-4 Gunnarsson LG, Lindberg G, Söderfeldt B, Axelson O: The mortality of motor neuron disease in Sweden. Arch Neurol 1990;47:42_ 46.

5 Gunnarsson LG, Palm R: Motor neuron disease and heavy manual labour: an epidemiologic survey of Värmland County, Sweden. Neuroepidemiology 1984;3:195-206. 
6 http://www.socialstyrelsen.se/register/dodsorsaksregistret (accessed 29 April 2010, 15 Nov 2011).

7 http://www.scb.se (accessed 15 May 2010, 15 Nov 2011).

8 Hennekens $\mathrm{CH}$, Buring JE: Epidemiology in Medicine. Boston, Little, Brown, 1987, pp 66-73.

$\checkmark 9$ Riise T, Nortvedt MW, Ascherio A: Smoking is a risk factor for multiple sclerosis. Neurology 2003;8:1122-1124.

10 Gallo V, Bueno-De-Mesquita HB, Vermeulen R, Andersen PM, Kyrozis A, Linseisen J, et al: Smoking and risk for amyotrophic lateral sclerosis: analysis of the EPIC cohort. Ann Neurol 2009;4:378-385.

11 Hawkes CH, Cavanagh B, Fox AJ: Motorneuron disease: a disorder secondary to solvent exposure? Lancet 1989;i:73-76.
2 Landtblom AM, Flodin U, Söderfeldt B, Wolfson C, Axelson O: Organic solvents and multiple sclerosis: a synthesis of the current evidence. Epidemiology 1996;7:429-433.

13 Landtblom AM: Exposure to organic solvents and multiple sclerosis. Neurology 1997; 49(2 suppl 2):S70-S74.

14 Lauer K: Environmental risk factors in multiple sclerosis. Expert Rev Neurother 2010; 10:421-440.

15 Olsson T, Hillert J: The genetics of multiple sclerosis and its experimental models. Curr Opin Neurol 2008;21:255-260.

16 Ahlgren C, Odén A, Lycke J: High nationwide prevalence of multiple sclerosis in Sweden. Mult Scler 2011;17:901-908.
Johansson LA, Björkestam C, Westerling R: Unexplained differences between hospital and mortality data indicated mistakes in death certification: an investigation of 1,094 deaths in Sweden during 1995. J Clin Epidemiol 2009;62:1202-1209.

18 Fang F, Valdimarsdóttir U, Bellocco R, Ronnevi LO, Sparén P, Fall K, Ye W: Amyotrophic lateral sclerosis in Sweden, 19912005. Arch Neurol 2009;66:515-519.

19 Malmgren M, Valdiviezo NL, Visscher BR, Clark VA, Detels R, Fukumoto M, Dudley JP: Underlying causes of death as recorded for multiple sclerosis: associated factors. J Chronic Dis 1983;36:699-705.

-20 Goldacre MJ, Duncan ME, Cook-Mozzafari $\mathrm{P}$, Griffit M: Trends in mortality rates comparing underlying-causes and multiplecause coding in an English population 19791998. J Publ Health Med 2003;25:249-253. 